\title{
ANOMALIES IN LIVER ARTERIAL BLOOD SUPPLY AND THEIR IMPORTANCE FOR HEPATIC SURGERY
}

\author{
René Vobořill, Jana Weberová ${ }^{2}$, Josef Dvořák ${ }^{3}$ \\ Charles University in Prague, Faculty of Medicine in Hradec Králové: Department of Surgery ${ }^{1}$, Department of Oncology ${ }^{3}$; \\ Charles University in Prague, Faculty of Pharmacy: Department of Biological and Medical Sciences ${ }^{2}$
}

Summary: Liver arterial system in humans presents wide variability. Knowledge of the variability is important for operation in this region (e.g. portcatheter implantation for regional intraarterial chemotherapy in patients with liver malignancy). The purpose of this study is to determine types of variation of liver artery system and their frequency in Czech population. The research was based on the evaluation of abdominal arteriograms, arteriography findings were confirmed during operations. There were found various anatomical relationships in this area, which may be divided into five types: type I. - standard organization occured in $75.6 \%$ of cases; type II. - presence of accessory artery ( $8.2 \%)$; type III. - variation of hepatic artery origin ( $7.4 \%)$; type IV. - the anomalous origin of gastroduodenal artery (6.9\%) and type V. - combination of varieties $(1.9 \%)$. The most often was the type I that occured in three quaters of cases approximately.

Key words: Hepatic artery; Variation; Liver arterial blood supply

\section{Introduction}

Method of liver intraarterial regional chemotherapy (administration of anticancer drugs directly into hepatic artery via portcatheter) is a hopeful way for the treatment of the primary and secondary malignancy of this organ. For implantation of the portcatheter into hepatic artery it is necessary to know the anatomical relationship, especially the organization of arterial system. Textbooks introduce usually the "standard“, anatomical variability is mentioned only marginally. However, the anomalous organization of liver artery system is quite common in clinical practice. The purpose of this study is to determine types of variation of liver artery system and their frequency in Czech population.

\section{Material and methods}

The research of arterial liver blood supply types was based on evaluation of 160 abdominal arteriograms of persons with known sex and age, 89 males and 71 females. The mean age was $61.3 \pm 9.7$ years $^{\mathrm{x}}$, range $33-79$ years.

The arteriographic examinations were performed during eleven years period (1991-2001) in patients suffering from primary or secondary liver malignancy. Seldinger method via femoral artery was used. Determination of liver arterial blood supply type was necessary to know for following portcatheter implantation and possible liver resection. Angiography findings (confirmed during operation) were drawn in preparatory schemes. The acquired results were evaluated statistically, photographic documentation was made in the most important findings.

\section{Results}

Anatomical organization found in our study can be divided into five types (tab. 1).

The patients with "standard" organization of liver arterial system were included into typ I (see Fig. 1). In these cases the common hepatic artery began from abdomen celiac trunk (Haller's tripod) and divided into two branches gastroduodenal artery and hepatic artery. The gastroduodenal artery gave off right gastroepiploic artery to the greater curvature and continued as superior pancreaticoduodenal artery which formed an anastomosis with inferior pancreaticoduodenal artery originating from superior mesenteric artery. The hepatic artery passed inside the hepatoduodenal ligament together with common bile duct and portal vein to the porta hepatis where it divided into two branches for the liver. The right gastric artery running back toward the lesser curvature of the stomach originated from hepatic artery, the cystic artery for gallbladder usually started from the right branch of hepatic artery. This type of anatomical organization was present in our group in 121 patients, i.e. $75.6 \%(68.9-82.3 \%)^{*}$.

The typ II (see Figs. 2,3,4) is characterized by presence of accessory artery. The accessory artery is such an artery 
Tab. 1: Five types of liver artery blood supply organization.

\begin{tabular}{|c|c|c|c|c|}
\hline Type & & Frequency & $\%$ & $\begin{array}{c}\text { Confidence } \\
\text { interval }\end{array}$ \\
\hline Type I (standard organization) & & 121 & 75.6 & $68.9-82.3$ \\
\hline \multirow{3}{*}{$\begin{array}{l}\text { Type II } \\
\text { (accessory hepatic a.) }\end{array}$} & II.a - from celiac trunk & 2 & 1.3 & $0-3.1$ \\
\hline & II.b - from left gastr.artery & 8 & 5.0 & $1.6-8.4$ \\
\hline & II.c - from superior mes.a. & 3 & 1.9 & $0-4.0$ \\
\hline \multirow{3}{*}{$\begin{array}{l}\text { Type III } \\
\text { (var. of hepatic art. origin) }\end{array}$} & III.a - com.h.a. from sup.mes.a. & 4 & 2.5 & $0.1-4.9$ \\
\hline & III.b - right h.a. from sup.mes.a. & 7 & 4.3 & $1.2-7.4$ \\
\hline & III.c - left h.a. from left gastric a. & 1 & 0.6 & $0-1.8$ \\
\hline \multirow{4}{*}{$\begin{array}{l}\text { Type IV } \\
\text { (anomalous origin of gastrod.art.) }\end{array}$} & IV.a - GD artery from right hepat.artery & 5 & 3.1 & $0.4-5.8$ \\
\hline & IV.b - GD artery from.bifurc.com.hep.a. & 1 & 0.6 & $0-1.8$ \\
\hline & IV.c - two trunks of GD artery & 3 & 1.9 & $0-4.0$ \\
\hline & IV.d - absence of GD artery & 2 & 1.3 & $0-3.1$ \\
\hline Type V (combination of varieties) & & 3 & 1.9 & $0-4.0$ \\
\hline
\end{tabular}

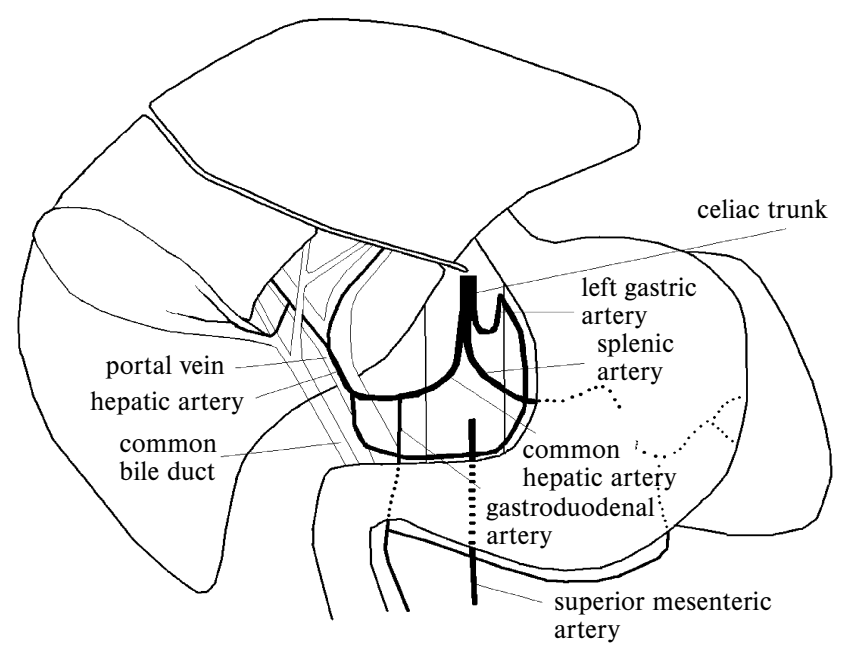

Fig. 1: Type I - standard organization.

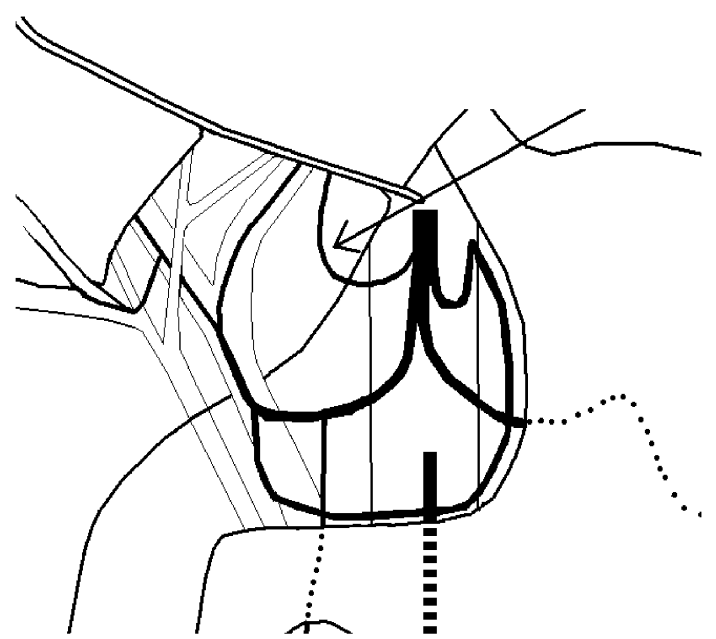

Fig. 2: Type IIa - accessory hepatic artery from celiac trunk.

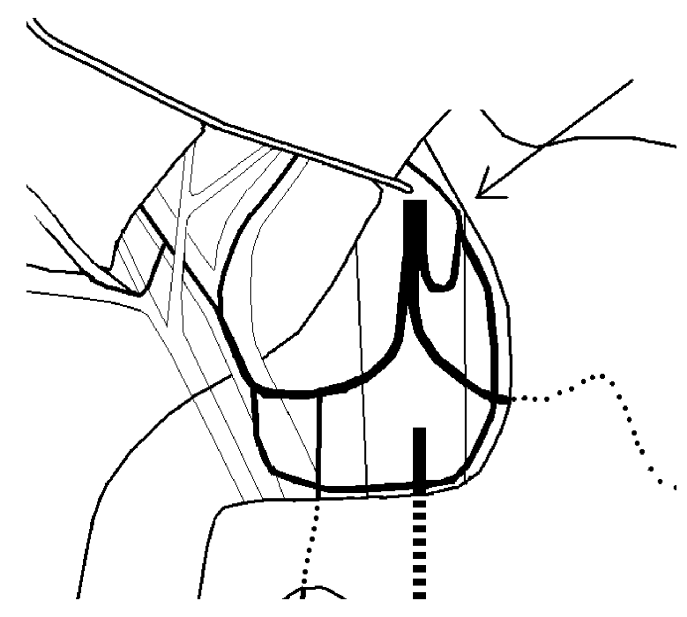

Fig. 3: Type IIb - accessory hepatic artery from left gastric artery.

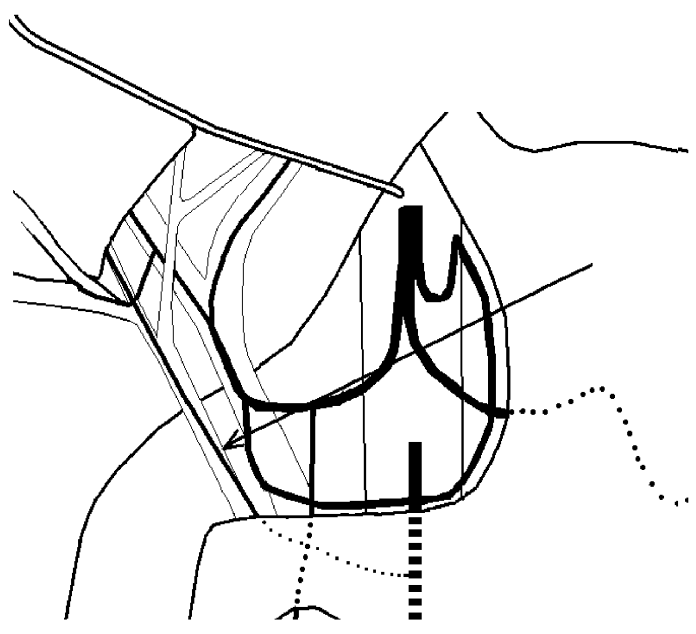

Fig. 4: Type IIc - accessory hepatic artery from superior mesenteric artery. 


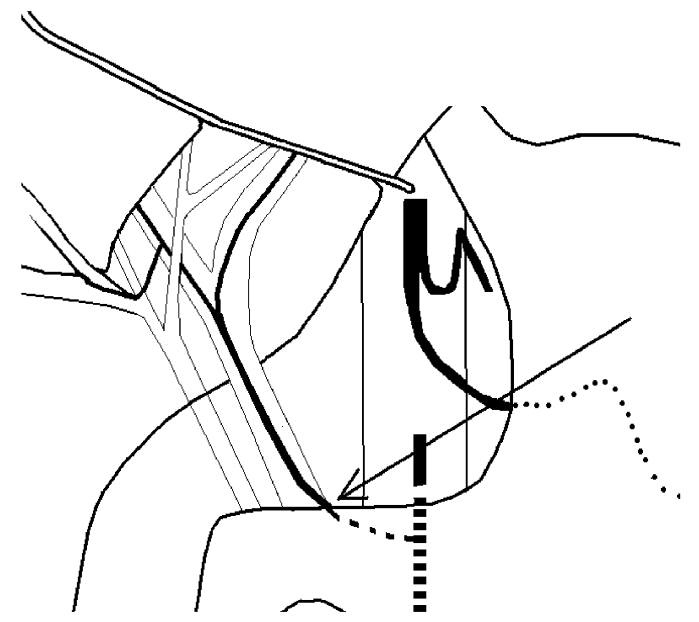

Fig. 5: Type IIIa - common hepatic artery from sup. mesenteric artery.

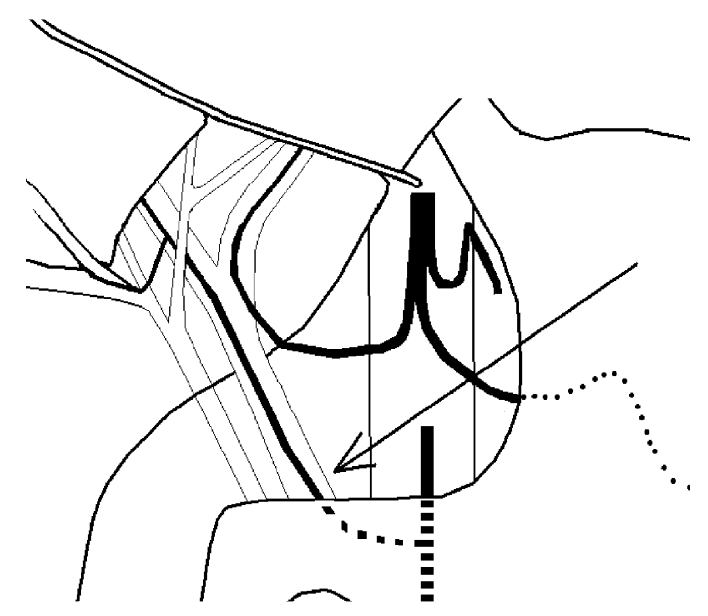

Fig. 6: Type IIIb - right hepatic artery from sup. mesenteric artery.

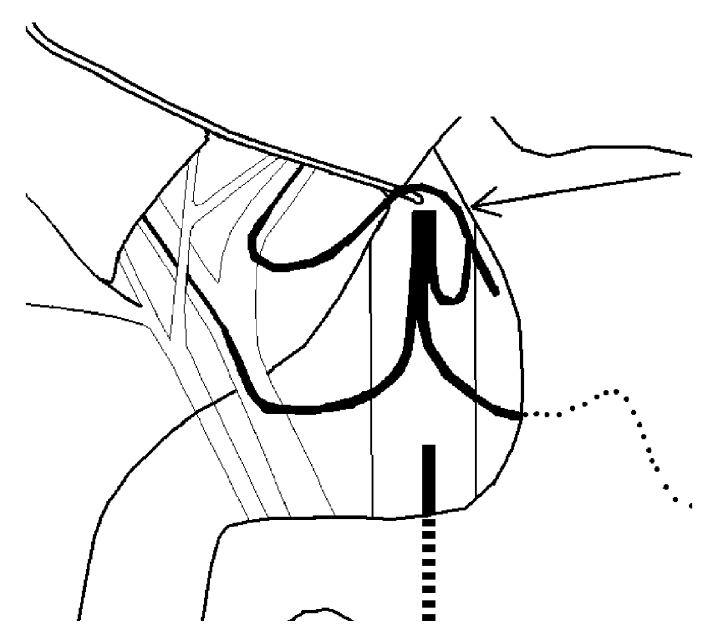

Fig. 7: Type IIIc - left hepatic artery from left gastric artery.

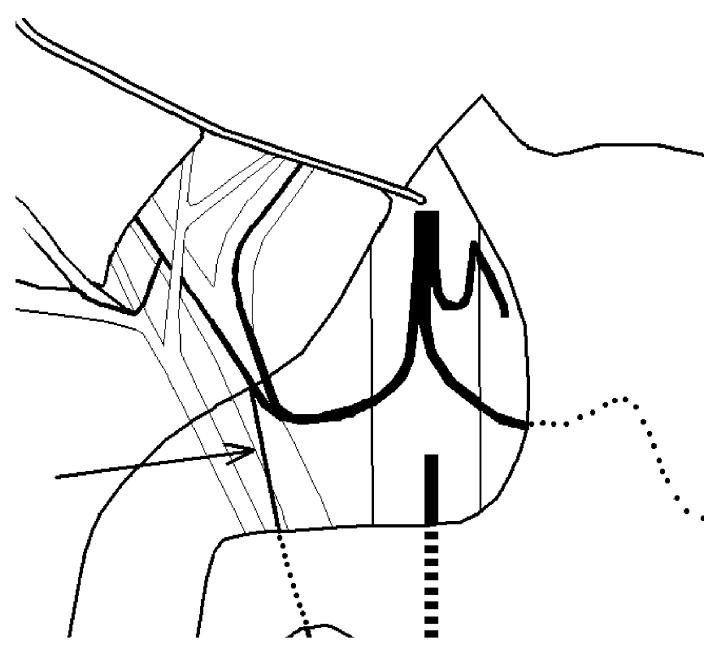

Fig. 8: Type IVa - gastroduodenal artery from right hepatic artery.

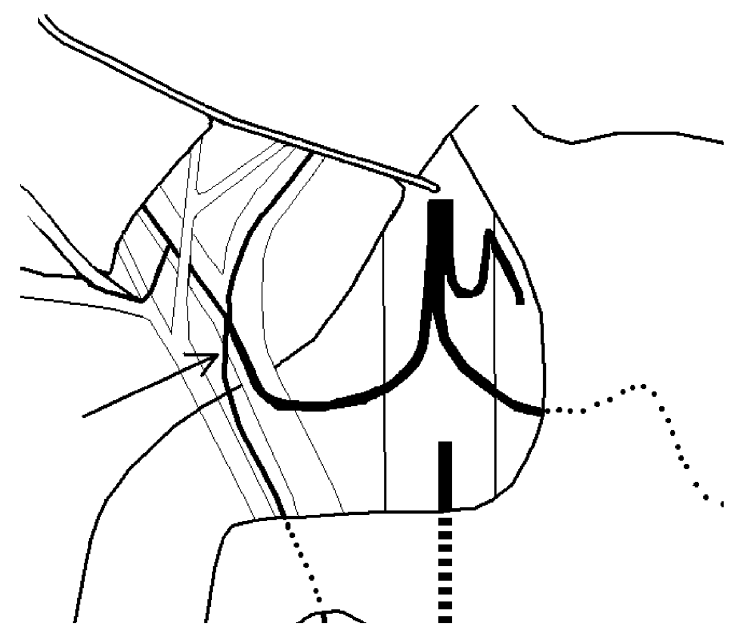

Fig. 9: Type IVb - gastroduodenal artery from common hepatic artery bifurcation.

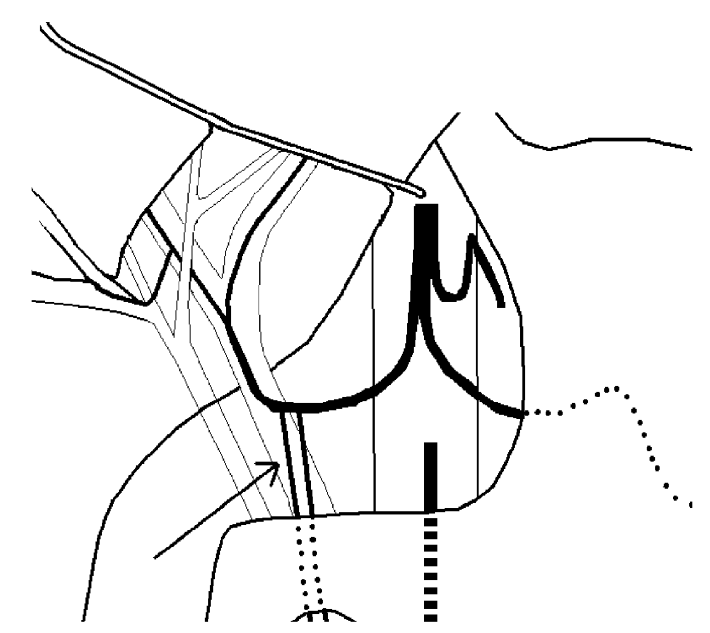

Fig. 10: Type IVc - two trunks of gastroduodenal artery. 


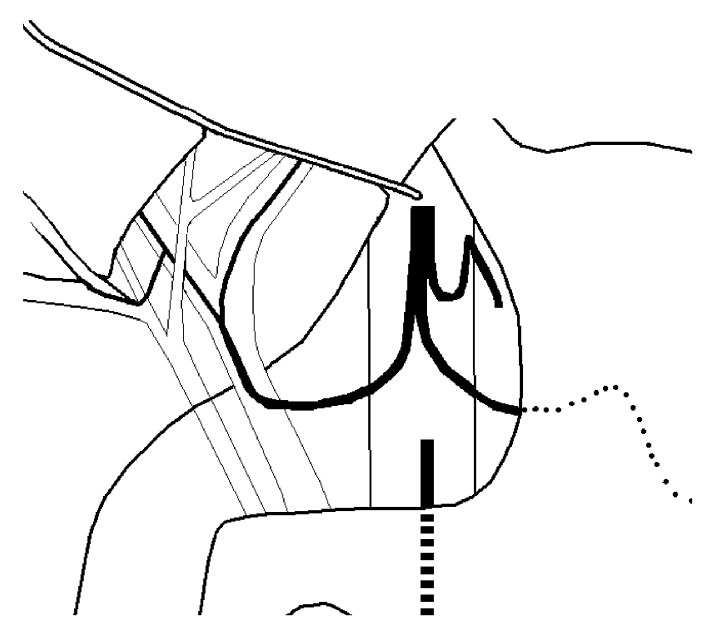

Fig. 11: Type IVd - absence of gastroduodenal artery.

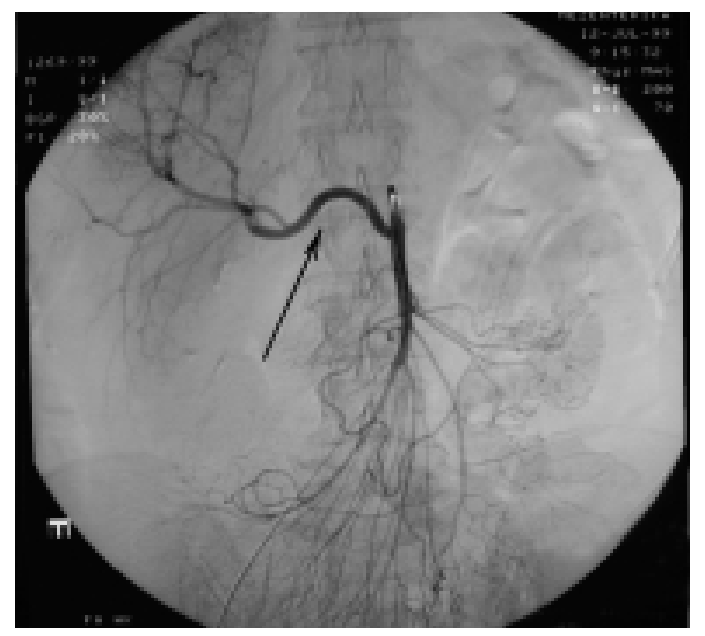

Fig. 12: Type IIIa - common hepatic artery from sup. mesenteric artery.

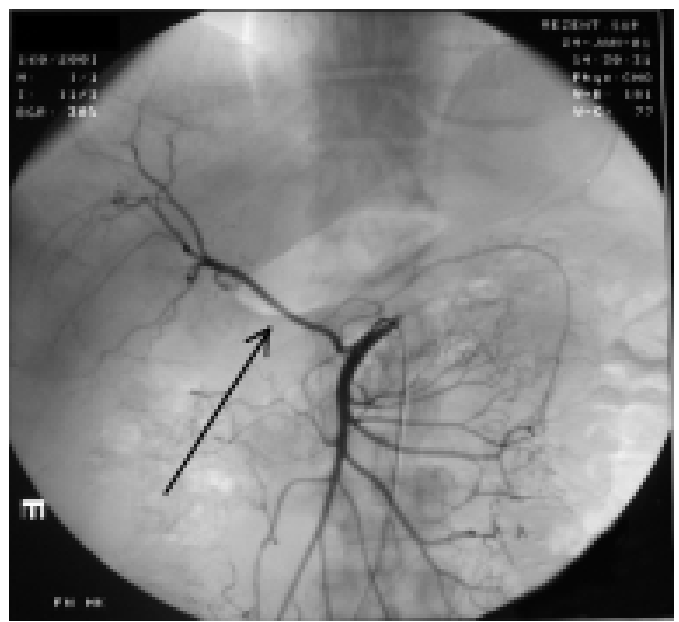

Fig. 13: Type IIIb - right hepatic artery from sup. mesenteric artery.

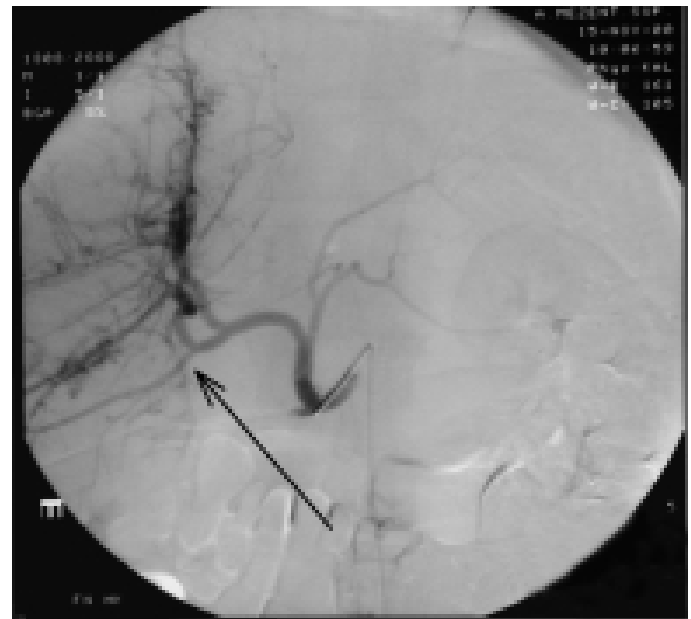

Fig. 14: Type IVa - gastroduodenal artery from right hepatic artery.

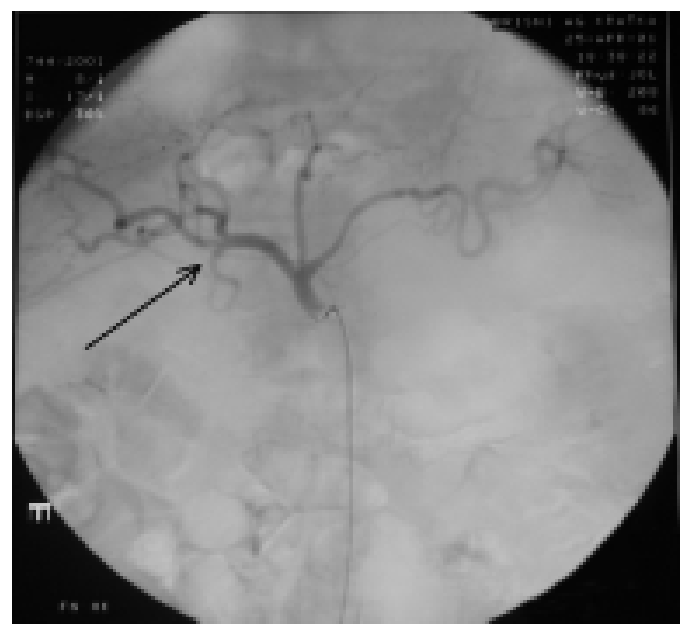

Fig. 15: Type IVa - gastroduodenal artery from common hepatic artery bifurcation.

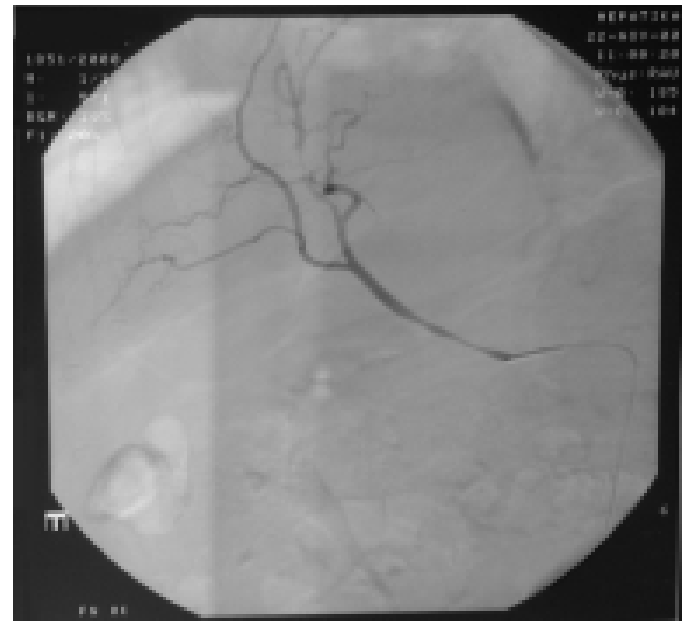

Fig. 16: Type IVd - absence of gastroduodenal artery. 
that appears in addition to normal liver blood supply via hepatic artery. Type II of the anatomical organization was found in 13 of our patients, i.e. $8.2 \%$ (3.9-12.5\%). Based on location of accessory artery origin it is possible to distinguish type IIa characterized by accessory artery originated from abdominal celiac trunk, observed in 2 cases, i.e. $1.3 \%(0-3.1 \%)$. Further type IIb where accessory artery started from left gastric artery, observed in 8 cases, i.e. $5.0 \%$ (1.6-8.4 \%). Finally type IIc, where accessory artery originated from superior mesenteric artery, was observed in 3 cases, i.e. $1.9 \%(0-4.0 \%)$.

The patients with variation of hepatic artery origin belong to the type III (see Figs. 5,6,7,12,13). This anomaly was observed in 12 patients, i.e. $7.4 \%(3.3-11.5 \%)$ and can be subdivided into three subgroups. The type IIIa, characterized by presence of common hepatic artery starting from superior mesenteric artery, was observed in 4 patients, i.e. $2.5 \%$ (0.1-4.9\%). The type IIIb, right hepatic artery beginning from superior mesenteric artery, was observed in 7 subjects, i.e. $4.3 \%(1.2-7.4 \%)$. Left hepatic artery originating from left gastric artery was typical for type IIIc. Type IIIc was present in 1 patient, i.e. $0.6 \%$ (0-1.8\%).

Type IV (see figs. 8,9,10,11,14,15,16), anomalous origin of gastroduodenal artery occured in 11 cases, i.e. $6.9 \%$ (3.0-10.8\%). Gastroduodenal artery starting from right hepatic artery belongs to the type IVa, that was seen in 5 subjects, i.e. $3.1 \%(0.4-5.8 \%)$. Type IVb, origin of gastroduodenal artery from bifurcation of common hepatic artery, was present in 1 case only, i.e. $0.6 \%$ (0-1.8 \%). Type IVc characterized by presence of two trunks of gastroduodenal artery occured in 3 patients, i.e. $1.9 \%$ (0-4.0\%). Type IVd, where absence of gastroduodenal artery was observed, was present in 2 subjects, i.e. $1.3 \%(0-3.1 \%)$.

Type V, combination of varieties, was observed altogether in 3 cases, i.e. $1.9 \%(0-4.0 \%)$. In two patients, i.e. $1.3 \%(0-3.1 \%)$, gastroduodenal artery originating from right hepatic artery + presence of accessory artery were seen. In 1 subject, i.e. $0.6 \%$ (0-1.8\%) right hepatic artery going from superior mesenteric artery + left accessory artery were present.

\section{Discussion}

Five types of liver arterial blood supply organizations were distinguished in the paper, but another classification was found in the literature, e.g. ten types of Michaels classification (4).

Anatomical textbooks usually describe standard, that is in this study marked as type I, and variation possibility is only mentioned (2). However, according to our observation the frequency of the type I represents only about three quaters of cases. Approximately $25 \%$ of all cases are "nonstandard" that corresponds with previously published studies (Lippert (6) 24 \%; Kowarada (5) 31-33\%; Noah (7)
$34 \%$ ). In contrast De Santis (4), who had studied 150 angiograms of hepatic artery in patients with liver tumours, had found normotype in only $52 \%$ of cases. The author explains that the reason of such variability can be partly accounted for neoplastic neovascularisation due to the malignancy.

The accessory artery supplying liver was repeatedly described in the literature $(1,3,6)$. Adachi (1) distinguishes 3 types of liver artery blood perfusion: 1. normal via hepatic artery; 2. anomalous with left accessory hepatic artery presence; 3 . anomalous with right accessory hepatic artery presence. The left accessory hepatic artery originating from left gastric artery only, the right accessory hepatic artery arising from superior mesenteric artery $(10.3 \%)$ or in $2 \%$ from Haller's tripod (1). Lippert (6) in agreement with previous author asserts, that the most often case (it occures in $12 \%$ ) of this variation type is presence of accessory artery for the left liver lobe arising from left gastric artery, further accessory artery from superior mesenteric artery for right liver lobe (in $5 \%$ ) but that relatively unusual is accessory artery originating from Haller's tripod, from abdominal aorta or from gastroduodenal artery. Also based on our observation most frequently accessory liver artery arised from left gastric artery.

The hepatic artery branch is usually on the side of the less-developed accessory artery (1). New theory is proposed, saying that the anomalous origin of right or left hepatic artery (type IIIb, IIIc) could be initially accessory hepatic artery (type IIb, IIc), while branch of hepatic artery on the accessory hepatic artery side is rudimentary. This rudimentary branch then secondary disappears.

The abnormal hepatic artery origin is a quite often variety. Lippert (6) described as the most frequent situation, when right hepatic artery engenders from superior mesenteric artery (according to Lippert (6) in $10 \%$ of cases, in our group in $4,3 \%$ of cases). Lippert (6) asserts, that superior mesenteric artery participates on liver blood supply altogether in $24 \%$ of cases, but common hepatic artery originates from superior mesenteric artery in $3 \%$ of cases only (6).

Information about variations of gastroduodenal artery was not found in the literature, only Adachi (1) described a case of gastroduodenal artery origin from Haller's tripod. The combination of varieties is unusual and occures less frequently than in $4 \%$ of all cases (6). In our group it was in less than $2 \%$.

\section{Conclusion}

Increase of primary and especially secondary liver malignancy requires new approaches to the treatment of this disease. One of the new treatment possibilities is represented by the method of intraarterial regional chemotherapy, which requires excellent knowledge of anatomical organization of arterial liver blood supply. 


\section{References}

1. Adachi B. Das Arteriensystem der Japaner. Band II. Verlag der Keiserlich, Japanischen Universität zu Kyoto, 1928:18-71.

2. Borovanský L, Hromada J, Kos J, Zrzavý J, Žlábek K. Soustavná anatomie člověka. Díl II. Praha: Státní zdravotnické nakladatelství, 1967:665-71.

3. Burke D, Earlam S, Fordy C, Allen-Mersh TG. Effect of aberrant hepatic arterial anatomy on tumour response to hepatic artery infusion of floxuridine for colorectal liver metastases. Br J Surg 1995;82:1098-100.

4. De Santis M, Ariosi P, Galo GF, Romagnoli R. Hepatic arterial vascular anatomy and its variants. Radiol Med 2000;100:145-51.

5. Kawarada Y, Das BC, Taoka H. Anatomy of the hepatic hilar area: the plate system. J Hepatobiliary Pancreat Surg 2000;7:580-6.

6. Lippert H. Arterienvarietäten. Med. Klin. 20/1968, München - Berlin - Wien Urban und Schwarzenberg, 1968:tab.17-20.

7. Noah EM, Klinzing S, Zwaan M, Schramm U, Bruch HP, Weiss HD. Normal variation of arterial liver supply in mesenterico-celiacography. Anat Anz 1995; 177:305-12.

Submitted February 2002.

Accepted April 2002.

MUDr. René Vobořil,

Rusek 106,

50003 Hradec Králové,

Czech Republic.

e-mail: rene.voboril@seznam.cz 